\title{
Drastic enhancement of photoresponsivity in $\mathrm{C}$-doped $\mathrm{BaSi}_{2}$ films formed by radio-frequency sputtering
}

T. Nemoto ${ }^{1}$, S. Matsuno ${ }^{1}$, T. Sato ${ }^{1,2}$, K. Gotoh ${ }^{3}$, M. Mesuda $^{4}$, H. Kuramochi ${ }^{4}$, K. Toko ${ }^{1}$, N. Usami ${ }^{3}$, T. Suemasu ${ }^{1}$

${ }^{1}$ Institute of Applied Physics, University of Tsukuba, Tsukuba, Ibaraki 305-8573, Japan

${ }^{2}$ Université Grenoble Alpes, CEA, CNRS, IRIG, SyMMES, 38000 Grenoble, France

${ }^{3}$ Graduate School of Engineering, Nagoya University, Nagoya 464-8603, Japan

${ }^{4}$ Tosoh Corporation, Advanced Materials Research Laboratory, Ayase, Kanagawa 252-1123, Japan

We formed carbon (C)-doped $\mathrm{BaSi}_{2}$ films by radio-frequency (RF) sputtering of $\mathrm{BaSi}_{2}$ and $\mathrm{SiC}$ targets simultaneously, and measured their optical properties. In the Raman spectra of $\mathrm{BaSi}_{2}$ films, peaks corresponding to vibrational modes of Si tetrahedra in the lattice of $\mathrm{BaSi}_{2}$ appear. On the other hand, in C-doped BaSi2 films, new peaks at around 260,310 , and $630 \mathrm{~cm}^{-1}$ other than those of $\mathrm{BaSi}_{2}$ films were observed. As the RF power of the $\mathrm{SiC}$ target $\left(P_{\mathrm{SiC}}\right)$ increased, these intensities increased. The absorption edge of $\mathrm{C}$-doped $\mathrm{BaSi}_{2}$ films was shifted to higher energies from $1.19 \mathrm{eV}$ to $1.30 \mathrm{eV}$ with increasing $P_{\mathrm{SiC}}$. We achieved the highest photoresponsivity of $1 \mathrm{~A} / \mathrm{W}$ ever achieved for undoped $\mathrm{BaSi}_{2}$ films at a bias voltage of $0.1 \mathrm{~V}$ applied between the top and bottom electrodes. The marked enhancement of photoresponsivity was interpreted to originate from the increased carrier lifetime in $\mathrm{C}$-doped $\mathrm{BaSi}_{2}$ films.

* Corresponding author at:

Institute of Applied Physics, Faculty of Pure and Applied Sciences, University of Tsukuba, Tsukuba, Ibaraki 305-8573, Japan

Electronic mail: suemasu@bk.tsukuba.ac.jp 


\section{INTRODUCTION}

Solar cells using silicon (Si) dominate the market, and their conversion efficiency $(\eta)$ is above $26 \% .{ }^{1}$ However, further improvement of $\eta$ is difficult to be achieved because the band gap $\left(E_{\mathrm{g}}\right)$ of crystalline $\mathrm{Si}$ (c-Si) is limited to $1.1 \mathrm{eV}^{2}$ Therefore, lots of studies have been conducted on various materials. ${ }^{3-6}$ Among such materials, we have focused on $\mathrm{BaSi}_{2}{ }^{7,8} \mathrm{BaSi}_{2}$ is composed of earth-abundant and non-toxic elements. It has a suitable $E_{\mathrm{g}}$ of $1.3 \mathrm{eV}$ for a single-junction solar cell, ${ }^{9}$ a large absorption coefficient $(\alpha)$ of $3 \times 10^{4} \mathrm{~cm}^{-1}$ at $1.5 \mathrm{eV}$, which is 40 times larger than that of c-Si. ${ }^{10-12}$ Moreover, BaSi2 has a large minority carrier diffusion length $L \approx 10 \mu \mathrm{m}^{13}$ due to its inactive grain boundary. ${ }^{14,15}$ Because of these excellent properties, $\mathrm{BaSi}_{2}$ is considered a thin-film solar cell material. In previous studies, we have achieved $\eta=9.9 \%$ in $\mathrm{p}-\mathrm{BaSi}_{2} / \mathrm{n}-\mathrm{Si}$ heterojunction solar cells fabricated by molecular beam epitaxy (MBE) ${ }^{16,17}$ Furthermore, we have demonstrated the operation of $\mathrm{BaSi}_{2}$ homojunction solar cells. ${ }^{18}$ However, an MBE method is not practical for large area deposition. On the other hand, vacuum evaporation is one of the techniques to deposit large-area thin films. There have been lots of studies about the formation of $\mathrm{BaSi}_{2}$ films by vacuum evaporation. ${ }^{19-23}$ Recently, we have demonstrated the formation of $\mathrm{BaSi}_{2}$ films by sputtering, ${ }^{24,25}$ and achieved photoresponsivities as high as those of $\mathrm{BaSi}_{2}$ films by MBE. ${ }^{24,25}$ From the viewpoint of solar cell applications, it is desirable to establish so called a bandgap-engineering technique in $\mathrm{BaSi}_{2}$. In general, the optimum $E_{\mathrm{g}}$ for a single junction solar cell is $1.4 \mathrm{eV}^{26}$ In a Si-based tandem solar cell, the most suitable $E_{\mathrm{g}}$ for a top cell material is $1.6-1.7 \mathrm{eV}^{27}$ Thus far, we have achieved the expansion of $E_{\mathrm{g}}$ from 1.3 to $1.4 \mathrm{eV}$ in $\mathrm{Ba}_{1-\mathrm{x}} \mathrm{Sr}_{\mathrm{x}} \mathrm{Si}_{2}$, wherein nearly half of the $\mathrm{Ba}$ atoms were replaced with isoelectric $\mathrm{Sr}$ atoms. ${ }^{28}$ However, as the $x$ value increases much further, $\mathrm{SrSi} 2$ was formed. ${ }^{28}$ According to firstprinciple calculation by Imai and Watanabe, $E_{\mathrm{g}}$ can be increased significantly by substitution of $\mathrm{Si}$ atoms with isoelectric $\mathrm{C},{ }^{29}$ wherein the $E_{\mathrm{g}}$ of $\mathrm{Ba}\left(\mathrm{Si}_{1-\mathrm{x}} \mathrm{C}_{\mathrm{x}}\right)_{2}$ is expected to increase by approximately 1.4 times than that of $\mathrm{BaSi}_{2}$ at $x=0.5$. However, there has been no experiment on C-doped $\mathrm{BaSi}_{2}$ films.

In this work, we formed $\mathrm{C}$-doped $\mathrm{BaSi}_{2}$ films by sputtering and investigated the optical properties of the films. In contrast to our prediction, there was not so much increase in $E_{\mathrm{g}}$ by C doping; however, the photoresponsivity of $\mathrm{C}$-doped $\mathrm{BaSi}_{2}$ films was significantly enhanced compared to undoped ones.

\section{EXPERIMENTAL METHOD}


Czochralski (CZ)-n-Si (111) substrate (resistivity $\rho<0.01 \Omega \mathrm{cm}$ ) and float zone (FZ) n-Si (111) substrate $(\rho>10000 \Omega \mathrm{cm})$ were ultrasonically cleaned with acetone, methanol, and water and then introduced into a helicon-wave excited plasma sputtering system (ULVAC MB 00 -1040). A 2 inch-diameter polycrystalline stoichiometric $\mathrm{BaSi}_{2}$ target made by Tosoh Corporation and a 1-inch or a 2-inch $\mathrm{SiC}$ target was used for the growth. In order to form stoichiometric $\mathrm{BaSi}_{2}$ films, 3 pieces of platelike Ba sources $\left(1.0 \mathrm{~cm}^{2}\right)$ were placed on the $\mathrm{BaSi} 2$ target. ${ }^{24} \mathrm{We}$ attempted to grow $\mathrm{C}$-doped $\mathrm{BaSi}_{2}$ films on a heated $\mathrm{Si}(111)$ substrate at $600{ }^{\circ} \mathrm{C}$ by sputtering these targets simultaneously. The Ar flow rate was set at $10 \mathrm{sccm}$. The sputtering pressure was set to 1.0 Pa. The radio frequency $(\mathrm{RF})$ power for $\mathrm{BaSi}_{2}\left(P_{\mathrm{BaSi}}\right)$ was varied from 30 to $50 \mathrm{~W}$ and that for $\mathrm{SiC}$ $\left(P_{\mathrm{SiC}}\right)$ was varied from 50 to $200 \mathrm{~W}$ to change the amount of $\mathrm{C}$ added in the $\mathrm{C}$-doped $\mathrm{BaSi}_{2}$ films. Table I summarizes the deposition conditions of samples. After the growth of $\mathrm{BaSi}_{2}$ films, we deposited a $3 \mathrm{~nm}$-thick amorphous Si layer by sputtering to prevent surface oxidation. ${ }^{30,31}$ Finally, for photoresponsivity measurement, $80 \mathrm{~nm}$ indium-tin oxide (ITO) surface electrodes with a diameter of $1 \mathrm{~mm}$ were deposited on $\mathrm{BaSi}_{2}$ on a CZ-Si substrate, and $150 \mathrm{~nm}$ Al electrode was deposited on the back surface by a magnetron RF-sputtering.

Raman spectroscopy (JASCO NRS-5100) equipped with a frequency-doubled $\mathrm{Nd}$ :YAG laser (532 nm, $5.1 \mathrm{~mW}$ ) was used to investigate the change of Raman spectra due to the effect of $\mathrm{C}$ atoms added. We measured the photoresponsivity of samples by a lock-in technique with a xenon lamp as a light source and a $25-\mathrm{cm}$-focal-length single monochromator (BunkoKeiki SM-1700 A and RU-60 N). Excess carrier lifetime of C-doped BaSi2 films on FZSi substrates was also measured by microwave-detected photoconductivity decay ( $\mu$-PCD) measurement (Kobelco, LTA -1512 EP). Depth profiles of C atoms were evaluated by secondary ion mass spectrometry (SIMS). All measurements were performed at room temperature.

The vibrational frequency calculation at $\Gamma$ point was performed with QUANTUMN ESPRESSO $\operatorname{code}^{32}$ within the framework of ab initio pseudopotential density functional perturbation theory. ${ }^{33}$ We employed the norm-conserving pseudopotentials with generalized gradient approximation in Troullier-Martins type $\mathrm{e}^{34}$ and the cut-off energy of the plane-wave basis sets was $60 \mathrm{Ry}$. For $k$ points in the Brillouin zone, a $3 \times 4 \times 2$ Monkhorst-Pack mesh was used for a perfect crystal (with an orthorhombic cell). Relaxation was performed until the total energy changed by less than $10^{-5}$ a.u. and the components of forces were smaller than $10^{-4}$ a.u. during geometry optimization. 
Table I Sample preparation detail; RF Power set for $\mathrm{BaSi}_{2}$ target $\left(P_{\mathrm{BaSi}}\right)$ and $\mathrm{SiC}$ target $\left(P_{\mathrm{SiC}}\right)$, and layer thickness were specified.

\begin{tabular}{|c|c|c|c|}
\hline Sample & $P_{\mathrm{BaSi} 2}(\mathrm{~W})$ & $P_{\mathrm{SiC}}(\mathrm{W})$ & Thickness $(\mathrm{nm})$ \\
\hline $\mathrm{A}$ & 50 & 0 & 290 \\
\hline $\mathrm{B}$ & 30 & 70 & 200 \\
\hline $\mathrm{C}$ & 30 & 100 & 370 \\
\hline $\mathrm{D}$ & 50 & 70 & 430 \\
\hline $\mathrm{E}$ & 50 & 150 & 270 \\
\hline F & 50 & 200 & 360 \\
\hline
\end{tabular}

\section{RESULTS AND DISCUSSION}

First, we confirmed the presence of $\mathrm{C}$ atoms in the deposited films by SIMS. Figure 1 shows the SIMS depth profiles of $\mathrm{C}$ atoms in $\mathrm{C}$-doped $\mathrm{BaSi}_{2}$ films in samples $\mathrm{D}$ and $\mathrm{F}$. The concentration of $\mathrm{C}$ increased with $P_{\mathrm{SiC}}$, and is uniformly distributed in the films. The concentration of $\mathrm{C}$ of both samples was over $10^{22} \mathrm{~cm}^{-3}$, which was the same order of Si. According to Ref [29], the concentration of $C$ was sufficient for $E_{\mathrm{g}}$ to increase. Note that the measured $\mathrm{C}$ concentration was determined semi-quantitatively on the basis of C-doped crystalline Si films, and thus contained a certain amount of errors because reference samples, wherein a controlled number of $\mathrm{C}$ atoms are doped in $\mathrm{BaSi}_{2}$, have not yet been prepared.

Figure 2(a) presents the experimentally obtained Raman spectra of all the samples, while Figs. 2(b) and 2(c) show the schematics of vibration modes of Si tetrahedra with a $\mathrm{C}$ atom positioned at a Si substitutional site and at an interstitial $4 c$ site of the $\mathrm{BaSi}_{2}$ lattice, respectively. For sample A, undoped $\mathrm{BaSi}_{2}$ films, Raman lines originating from Si tetrahedra in the lattice of BaSi2 were observed. ${ }^{35}$ For C-doped BaSi2 films in samples B-D, we can state that these peaks gradually shifted to smaller wavenumbers and the spectral shape changed. With increasing $P_{\mathrm{SiC}}$ much further, in samples $\mathrm{E}$ and $\mathrm{F}$, the peak intensity of $\mathrm{Ag}$ mode at $490 \mathrm{~cm}^{-1}$ sharply decreased and peaks at around 260,310, and $630 \mathrm{~cm}^{-1}$ became dominant. These peaks were not observed in sample A, undoped BaSi2 films. ${ }^{36}$ Regarding Raman peaks at around $630 \mathrm{~cm}^{-1}$ in samples AF in Fig. 2(a), we calculated vibration modes of a C-containing Si tetrahedron and it was found that the $\mathrm{Ag}$ mode shifts to $639.6 \mathrm{~cm}^{-1}$ as shown in Fig. 2(b). This value was close to the peaks around $630 \mathrm{~cm}^{-1}$ marked by triangles ( $\mathbf{\nabla}$ ) in Fig. 2(a). As for the intense Raman peak at around $260 \mathrm{~cm}^{-1}$ in samples B-F in Fig. 2(a), this peak is close to the vibration mode at $265.4 \mathrm{~cm}^{-1}$ obtained by calculation as shown in Fig. 2(c). We therefore regard this peak to originate from 
$\mathrm{C}$ atoms at the $4 c$ site. At present, we can not specify the origin of a peak at around $310 \mathrm{~cm}^{-1}$ in Fig. 2(a); however, we can at least state that $\mathrm{C}$ atoms substitute for Si sites but they start to occupy the interstitial $4 c$ site with further increasing the amount of doped $\mathrm{C}$ atoms. Note that Raman peaks corresponding to crystalline $\mathrm{SiC}$ were not observed in all the samples. We also compared the Raman spectrum of sample B with that of sample D. Although they were deposited at the same $P_{\mathrm{SiC}}$ of $70 \mathrm{~W}$, the intensities of Raman peaks in sample $\mathrm{D}$, grown under higher $P_{\mathrm{BaSi}}$, were higher than those of sample $\mathrm{B}$ in the range $250-300 \mathrm{~cm}^{-1}$. We observed the plasma color around the $\mathrm{BaSi}_{2}$ target changed from red to green as $P_{\mathrm{BaSi}}$ was increased. The green-colored emission comes from excited $\mathrm{Ba}$ atoms. Thus, $\mathrm{C}$-doped $\mathrm{BaSi}_{2}$ films in sample $\mathrm{D}$ was formed under Ba-rich conditions compared to sample B, and C-related Raman peaks became intense in such films.

We measured the absorption edge of $\mathrm{C}$-doped $\mathrm{BaSi}_{2}$ films. First, we measured photoresponsivity spectra and derived the absorption edge from the spectra around the band gap. In all the samples, the photoresponsitiy increased sharply for photon energies greater than the band gap of $\mathrm{BaSi}_{2}$, meaning that the signals came mostly from the $\mathrm{BaSi}_{2}$ films. The contribution of the Si substrate was negligibly small because of the use of heavily doped substrates for the photoresponsivity measurement. The generation rate of electron-hole pairs, $G$, generated per unit time and volume at a distance $x$ from the surface of semiconductor follows Eq. (1),

$$
G \propto \alpha \frac{P_{\mathrm{opt}}}{\square \omega} \exp (-\alpha x)
$$

where $\square \omega$ is the photon energy, and $P_{\text {opt }}$ is the incident optical power per unit area for a given photon energy $\square \omega$. The photocurrent, $I_{\mathrm{p}}$, is proportional to $G$, and the photoresponsivity is proportional to $I_{\mathrm{p}} /\left(P_{\text {opt }} \square \omega\right)$. Although $\alpha$ depends on $\square \omega, \exp (-\alpha x)$ in Eq. (1) is much less dependent on $\square \omega$ around the absorption edge. This is because $\alpha$ is small around the absorption edge. Thus, photoresponsivity is likely to be proportional to $\alpha .^{37}$ Indirect band gap semiconductor like $\mathrm{BaSi}_{2}$ follows

$$
\alpha \propto\left(\square \omega-E_{\mathrm{g}} \pm E_{\text {phonon }}\right)^{2} .
$$

Here, $E_{\text {phonon }}$ is the phonon energy. Figure 3 presents plots of $\left[I_{\mathrm{p}} /\left(P_{\text {opt }} / \square \omega\right)\right]^{1 / 2}$ vs $\square \omega$ under a bias voltage $V_{\text {bias }}$ of $0.5 \mathrm{~V}$. In the lower photon energy region, the $\left[I_{\mathrm{p}} /\left(P_{\text {opt }} / \square \omega\right)\right]^{1 / 2}$ vs $\square \omega$ plot is linear, and the linear extrapolation to the axis gives the absorption edge. The absorption edge expanded from $1.19 \mathrm{eV}$ in sample $\mathrm{A}$ to $1.30 \mathrm{eV}$ in sample $\mathrm{F}$ with increasing $P \mathrm{SiC}$ from 0 
$\mathrm{W}$ to $200 \mathrm{~W}$, respectively. This absorption edge of $1.19 \mathrm{eV}$ for undoped $\mathrm{BaSi}_{2}$ films is approximately $0.16 \mathrm{eV}$ smaller than that by MBE. ${ }^{11}$ We recently explored a possibility to manipulate $E_{\mathrm{g}}$ values in undoped $\mathrm{BaSi}_{2}$ films by changing lattice constants $a, b$, and $c .{ }^{38} \mathrm{We}$ therefore ascribe this reduction in absorption edge between undoped $\mathrm{BaSi}_{2}$ films grown by $\mathrm{MBE}$ and those by sputtering to the lattice distortion. Here, we discuss the relationship between Raman spectra and the absorption edge. According to first-principle calculations, ${ }^{29}$ the expansion of absorption edge $\left(\sim E_{\mathrm{g}}\right)$ was anticipated by the substitution of some part of Si atoms with isoelectric $\mathrm{C}$ atoms.

As described above, the Raman peak intensity at around $630 \mathrm{~cm}^{-1}$ can be used as a measure to investigate how much of the $\mathrm{C}$ atoms substitute for Si sites. Therefore, focusing on this peak, we plotted the relative intensity of this peak normalized using the intensity of $\mathrm{Ag}_{\mathrm{g}}$ mode (490 $\mathrm{cm}^{-1}$ ) and the measured absorption edges in samples A, D, E, and F against $P_{\mathrm{SiC}}$ in Fig. 4 . As the peak intensity at $630 \mathrm{~cm}^{-1}$ increased, the absorption edge also increased. This result suggests that the expansion of the band gap occurs in accordance with calculation. As shown in Figs. 2(a) and 2(b), however, the number of $\mathrm{C}$ atoms in the Si substitutional site were quite limited. Thus, the challenge is how to increase $\mathrm{C}$ atoms in the Si sites.

Figure 5 shows the photoresponsivity spectra of samples measured under a bias voltage of $0.1 \mathrm{~V}$. It was found that the photoresponsivity was greatly improved in samples $\mathrm{C}$ and $\mathrm{D}$ compared with that of undoped $\mathrm{BaSi}_{2}$. The photoresponsivity exceeds $1 \mathrm{~A} / \mathrm{W}$ at a bias voltage of $0.1 \mathrm{~V}$ for sample $\mathrm{D}$. This value is the highest ever achieved for $\mathrm{BaSi}_{2}$ films including MBEgrown $\mathrm{BaSi}_{2}$ films. Hence we attribute this enhancement of photoresponsivity to the improvement of carrier lifetime by adding $\mathrm{C}$ atoms in BaSi2. In contrast, however, the photoresponsivity of samples $\mathrm{B}$, E, and $\mathrm{F}$ were decreased compared to that of undoped $\mathrm{BaSi}_{2}$ films in sample A. C-doped BaSi2 films in sample B is considered to be formed under Si-rich conditions than in sample $\mathrm{D}$ because of smaller $P_{\mathrm{BaSi} 2}$; it was $30 \mathrm{~W}$ for sample $\mathrm{B}$ and $50 \mathrm{~W}$ for sample D. When Ba-to-Si composition ratios in $\mathrm{BaSi}_{2}$ deviate from stoichiometry, the photoresponsivity of the films degrades significancy. ${ }^{39}$ On the other hand, in samples E and F, the photoresponsivity was deteriorated probably due to two factors. One possibility is that $\mathrm{BaSi}_{2}$ films were formed under Si-rich conditions since $P_{\mathrm{SiC}}$ was set large and therefore a large amount of Si atoms was supplied to the film as well as $\mathrm{C}$ atoms. Another possibility is that a large amount of $\mathrm{C}$ in the film may act as defects. However, we are not sure for certain at the moment. On the basis of these results, we conclude that the photoresponsivity of $\mathrm{BaSi}_{2}$ films was dramatically improved by adding a small amount of $\mathrm{C}$ atoms in $\mathrm{BaSi}_{2}$. The photoresponsivity 
is roughly proportional to the ratio of carrier lifetime to the carrier transit time. ${ }^{40}$ Therefore, we ascribe the enhancement of photoresponsivity to the increase of carrier lifetime and/or the decrease of carrier transit time. To confirm the increase of carrier lifetime, we performed $\mu$ PCD measurements on samples A, D, and E.

The photoexcitation of carriers was performed by a 5 -ns laser pulse in a spot with a 2$\mathrm{mm}$ diameter at a wavelength of $349 \mathrm{~nm}$. The light intensity was $1.3 \times 10^{5} \mathrm{~W} / \mathrm{cm}^{2}$. The photoconductivity decay was measured by the reflection of $26 \mathrm{GHz}$ microwave. The photoconductivity decay curves are shown in Fig. 6 . The carrier lifetime is defined as the time when the reflected microwave intensity reaches $e^{-1}$ of its initial intensity. The carrier lifetimes, $\tau_{1 / \mathrm{e}}$, were measured to be $4.6 \mu \mathrm{s}, 7.6 \mu \mathrm{s}$, and $3.1 \mu \mathrm{s}$ for samples A, D, and E, respectively. The longer the $\tau_{1 / \mathrm{e}}$ became, the higher the photoresponsivity of $\mathrm{BaSi}_{2}$ films was obtained, indicating that the photoresponsivity enhancement was verified by the increase of carrier lifetime. We attribute this improvement to the decrease of point defects in C-doped $\mathrm{BaSi}_{2}$ films. In undoped $\mathrm{BaSi} 2$ films, photoresponsivity and carrier lifetime were improved significantly by hydrogen (H) passivation. ${ }^{41} \mathrm{H}$ atoms in $\mathrm{BaSi} 2$ are considered to inactivate $\mathrm{Si}$ vacancies, which are most likely to form in $\mathrm{BaSi}_{2}{ }^{42}$ We therefore speculate that inactivation of $\mathrm{Si}$ vacancies by doping $\mathrm{C}$ atoms in $\mathrm{C}$-doped $\mathrm{BaSi}_{2}$ films occurs. These results indicate $\mathrm{C}$-doped $\mathrm{BaSi}_{2}$ films are very promising as light absorbing layers in a solar cell.

\section{CONCLUSION}

We formed C-doped $\mathrm{BaSi}_{2}$ films on $\mathrm{Si}(111)$ substrates by sputtering $\mathrm{BaSi}_{2}$ and $\mathrm{SiC}$ targets simultaneously and investigated their optical properties. In Raman spectra, the new peaks that were not observed in undoped $\mathrm{BaSi}_{2}$ films appeared in $\mathrm{C}$-doped $\mathrm{BaSi}_{2}$ films. The peak at around $630 \mathrm{~cm}^{-1}$ was regarded to show the vibrational mode of C-containing Si tetrahedra and the peak intensity increased with increasing $P_{\mathrm{SiC}}$. The absorption edge was expanded by approximately $0.1 \mathrm{~V}$ from $1.19 \mathrm{eV}$ to $1.30 \mathrm{eV}$ as $P_{\mathrm{SiC}}$ increased. The photoresponsivity depended significantly on $P_{\mathrm{SiC}}$ and exceeded $1 \mathrm{~A} / \mathrm{W}$ at a bias voltage of $0.1 \mathrm{~V}$ in the sample with a small amount of $\mathrm{C}$ added at $P_{\mathrm{SiC}}=70 \mathrm{~W}$. The enhancement of photoresponsivity was verified by the increase of carrier lifetime measured by $\mu-\mathrm{PCD}$, due probably to the reduction of Si vacancies in C-doped $\mathrm{BaSi} 2$ films.

\section{Acknowledgements}


This work was financially supported by JSPS KAKENHI Grant Numbers 17K18865 and 18H03767 and JST MIRAI. 


\section{Reference}

${ }^{1)}$ K. Yoshikawa, H. Kawasaki, W. Yoshida, K. Konishi, K. Nakano, T. Uto, D. Adachi, M.

Kakematsu, H. Uzu, and K. Yamamoto, Nat. Energy 2, 17032 (2017).

${ }^{2)}$ W. Shockley and H. J. Queisser, J. Appl. Phys. 32, 510 (1961).

3) P. Jackson, R. Wuerz, D. Hariskos, E. Lotter, W. Witte, and M. Powalla, Phys. Status Solidi RRL 10, 583 (2016).

4) X. Wu, Sol. Energy 77, 803 (2004).

5) J. Burschka, N. Pellet, S.-J. Moon, R. Humphry-Baker, P. Gao, M. K. Nazeeruddin, and M. Grätzel, Nature 499, 316 (2013).

${ }^{6)}$ W. S. Yang, J. H. Noh, N. J. Jeon, Y. C. Kim, S. Ryu, J. Seo, and S. I. Seok, Science 348, 1234 (2015).

7) T. Suemasu, Jpn. J. Appl. Phys. 54, 07JA01 (2015).

${ }^{8)}$ T. Suemasu and N. Usami, J. Phys. D 50, 023001 (2017).

${ }^{9)}$ K. Morita, Y. Inomata, and T. Suemasu, Thin Solid Films 508, 363 (2006).

${ }^{10)}$ D. B. Migas, V. L. Shaposhnikov, and V. E. Borisenko, Phys. Status Solidi B 244, 2611 (2007).

${ }^{11)}$ K. Toh, T. Saito, and T. Suemasu, Jpn. J. Appl. Phys. 50, 068001 (2011).

${ }^{12)}$ M. Kumar, N. Umezawa, and M. Imai, Appl. Phys. Express 7, 071203 (2014).

${ }^{13)}$ M. Baba, K. Toh, K. Toko, N. Saito, N. Yoshizawa, K. Jiptner, T. Sakiguchi, K. O. Hara, N. Usami, and T. Suemasu, J. Cryst. Growth 348, 75 (2012).

${ }^{14)}$ K. O. Hara, N. Usami, K. Nakamura, R. Takabe, M. Baba, K. Toko, and T. Suemasu, Appl. Phys. Express 6, 112302 (2013).

${ }^{15)}$ M. Baba, M. Kohyama, and T. Suemasu, J. Appl. Phys. 120, 085311 (2016).

16) S. Yachi, R. Takabe, K. Toko, and T. Suemasu, Appl. Phys. Lett. 109, 072103 (2016).

${ }^{17)}$ T. Deng, T. Sato, Z. Xu, R. Takabe, S. Yachi, Y. Yamashita, K. Toko, and T. Suemasu, Appl. Phys. Express 11, 062301 (2018).

${ }^{18)}$ K. Kodama, Y. Yamashita, K. Toko, and T. Suemasu, Appl. Phys. Express 12, 041005 (2019).

${ }^{19)}$ C. T. Trinh, Y. Nakagawa, K. O. Hara, R. Takabe, T. Suemasu, and N. Usami, Mater. Res. Express 3, 076204 (2016).

${ }^{20)}$ Kosuke O. Hara, C. T. Trinh, Y. Kurokawa, K. Arimoto, J. Yamanaka, K. Nakagawa, N. Usami, Thin Solid Films 636, 546 (2017).

${ }^{21)}$ T. Suhara, K. Murata, A. Navabi, Kosuke O. Hara, Y. Nakagawa, C. T. Trinh, Y. Kurokawa, T. Suemasu, K. L. Wang, and N. Usami, Jpn. J. Appl. Phys. 56, 05DB05 (2017). 
${ }^{22)}$ K. Takahashi, Y. Nakagawa, K. O. Hara, I. Takahashi, Y. Kurokawa, and N. Usami, MRS Adv. 3, 1435 (2018).

${ }^{23)}$ Kosuke O. Hara, K. Arimoto, J. Yamanaka, and K. Nakagawa, Jpn. J. Appl. Phys. 58, SBBF01 (2019).

${ }^{24)}$ S. Matsuno, R. Takabe, S. Yokoyama, K. Toko, M. Mesuda, H. Kuramochi, and T. Suemasu, Appl. Phys. Express 11, 071401 (2018).

${ }^{25)}$ S. Matsuno, T. Nemoto, M. Mesuda, H. Kuramochi, K. Toko, and T. Suemasu, Appl. Phys. Express 12, 021004 (2019).

${ }^{26)}$ A. Polman, M. Knight, E. C. Garnett, B. Ehrler, and W. C. Sinke, Science 352, 6283 (2016).

${ }^{27)}$ F. Meillaud, A. Shah, C. Droz, E. Vallat-Sauvain, and C. Miazza, Sol. Energy Mater. Sol. Cells 90, 2952 (2006).

${ }^{28)}$ K. Morita, M. Kobayashi, and T. Suemasu, Jpn. J. Appl. Phys. 45, L390 (2006).

${ }^{29)}$ Y. Imai and A. Watanabe, Intermetallics 18, 1432 (2010).

${ }^{30)}$ R. Takabe, S. Yachi, W. Du, D. Tsukahara, H. Takeuchi, K. Toko, and T. Suemasu AIP Adv. 6, 085107 (2016).

31) S. Yachi, R. Takabe, K. Toko, and T. Suemasu, Appl. Phys. Lett. 109, 072103 (2016).

${ }^{32)}$ P. Giannozzi, S. Baroni, N. Bonini, M. Calandra, R. Car, C. Cavazzoni, D. Ceresoli, G. L. Chiarotti, M. Cococcioni, I. Dabo, A. Dal Corso, S. de Gironcoli, S. Fabris, G. Fratesi, R. Gebauer, U. Gerstmann, C. Gougoussis, A. Kokalj, M. Lazzeri, L. Martin-Samos, N. Marzari, F. Mauri, R. Mazzarello, S. Paolini, A. Pasquarello, L. Paulatto, C. Sbraccia, S. Scandolo, G. Sclauzero, A. P. Seitsonen, A. Smogunov, P. Umari, and R. M. Wentzcovitch, J. Phys.:

Condens. Matter 21, 395502 (2009).

33) S. Baroni, S. d. Gironcoli, and P. Giannozzi, Rev. Mod. Phys. 73, 515 (2001).

${ }^{34)}$ We used Si.pbe-mt_fhi.UPF, Ba.pbe-mt_fhi.UPF, C.pbe-mt_fhi.UPF, from http://www.quantum-espresso.org.

${ }^{35)}$ H. Hoshida, N. Murakoso, T. Suemasu, and Y. Terai, Defect and Diffusion Forum 386, 43 (2018).

${ }^{36)}$ T. Sato, H. Hoshida, R. Takabe, K. Toko, Y. Terai and T. Suemasu, J. Appl. Phys. 124, 025301 (2018).

${ }^{37)}$ Y. Matsumoto, D. Tsukada, R. Sasaki, T. Mitsutomo, and T. Suemasu, Appl. Phys. Express 2021101 (2009).

${ }^{38)}$ D. A Shohonov, D. B. Migas, A. B. Filonov, and V. E. Borisenko, K. Takabe, and T. Suemasu, Thin Solid Films 686, 137436 (2019). 
${ }^{39)}$ R. Takabe, T. Deng, K. Kodama, Y. Yamashita, T. Sato, K. Toko, and T. Suemasu, J. Appl. Phys. 123, 045703 (2018).

${ }^{40)}$ S. M. Sze, Physics of Semiconductor Devices, $2^{\text {nd }}$ ed., John Wiley \& Sons, 1981.

${ }^{41)}$ Z. Xu, D. A. Shohonov, A. B. Filonov, K. Gotoh, T. Deng, S. Honda, K. Toko, N. Usami, D.

B. Migas, V. E. Borisenko, and T. Suemasu, Phys. Rev. Mater. 3, 065403 (2019).

${ }^{42)}$ M. Kumar, N. Umezawa, W. Zhou, and M. Imai, J. Mater. Chem. A 5, 25293 (2017). 
Fig. 1 SIMS depth profiles of C atoms of samples D and F.

Fig. 2 (a) Raman spectra of all samples with various values of $P_{\mathrm{SiC}}$ and $P_{\mathrm{BaSi}}$. Triangles ( $\mathbf{\nabla}$ ) indicate the vibrational mode due to C-containing Si tetrahedra in $\mathrm{BaSi}_{2}$ calculated by Quantum Espresso. Schematics of vibrational modes of Si tetrahedra with a $\mathrm{C}$ atom positioned (b) at a Si substitutional site and (c) at an interstitial $4 c$ site.

Fig. 3 Dependence of the square root of the photoresponsivity on photon energy at $V_{\text {bias }}=0.5 \mathrm{~V}$. We derived the absorption edge from the intercept.

Fig. $4 P_{\mathrm{SiC}}$ dependences of absorption edge of $\mathrm{C}$-doped $\mathrm{BaSi}_{2}$ films and the relative intensity of the peak at around $630 \mathrm{~cm}^{-1}$ with respect to the peak intensity of $\mathrm{Ag}$ mode $\left(490 \mathrm{~cm}^{-1}\right)$.

Fig. 5 Photoresponse spectra of undoped $\mathrm{BaSi}_{2}$ films (sample A) and C-doped $\mathrm{BaSi}_{2}$ films (samples B-F) with various $P_{\mathrm{SiC}}$ and $P_{\mathrm{BaSi} 2}$ at $V_{\text {bias }}=0.1 \mathrm{~V}$.

Fig. 6 Normalized photoconductivity decay curves of samples A, D, and E. Photoconductivity is normalized to the value at $t=0$. 


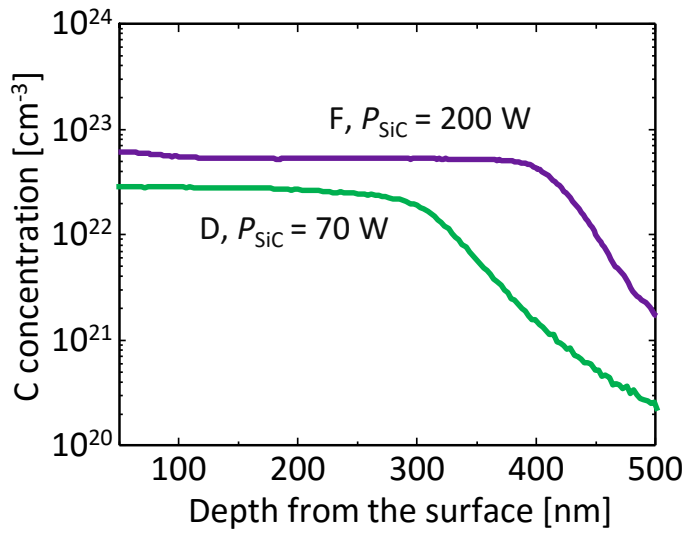

Fig. 1 


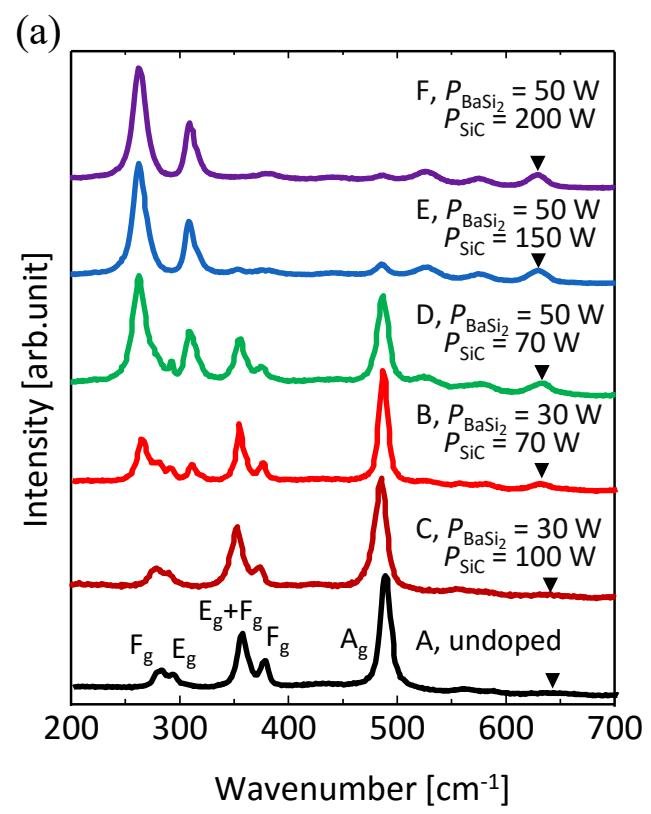

(b)

(c)

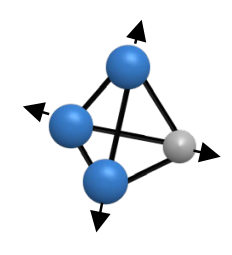

$639.6 \mathrm{~cm}^{-1}$

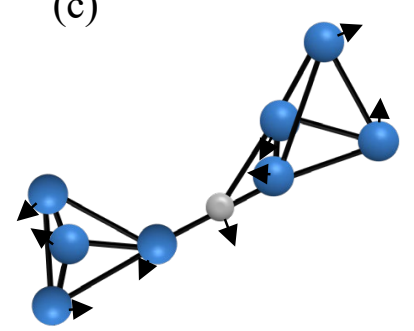

$265.4 \mathrm{~cm}^{-1}$

- $\mathrm{Si} \bigcirc \mathrm{C}$

Fig. 2 


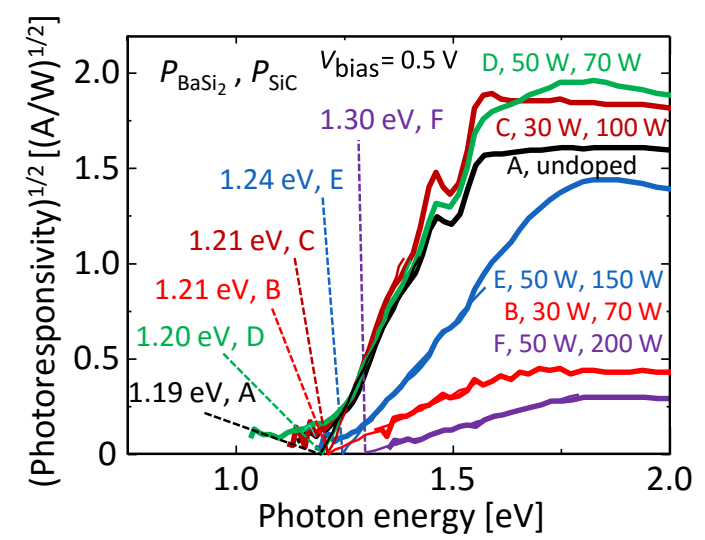

Fig. 3 


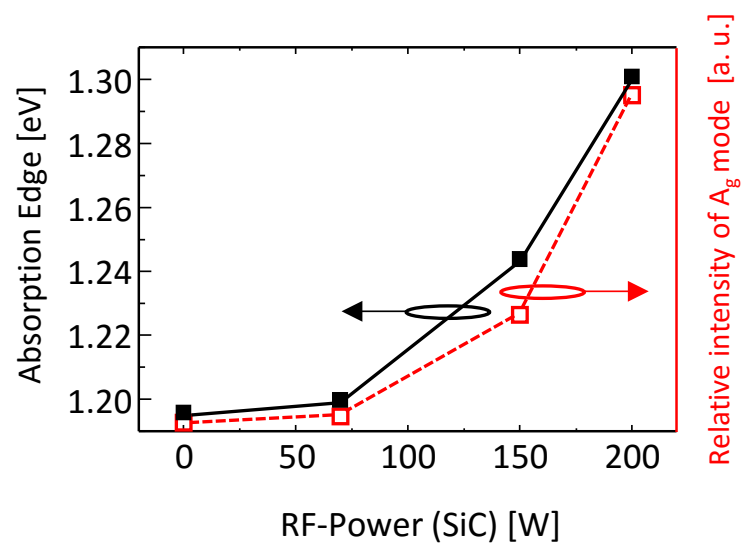

Fig. 4 


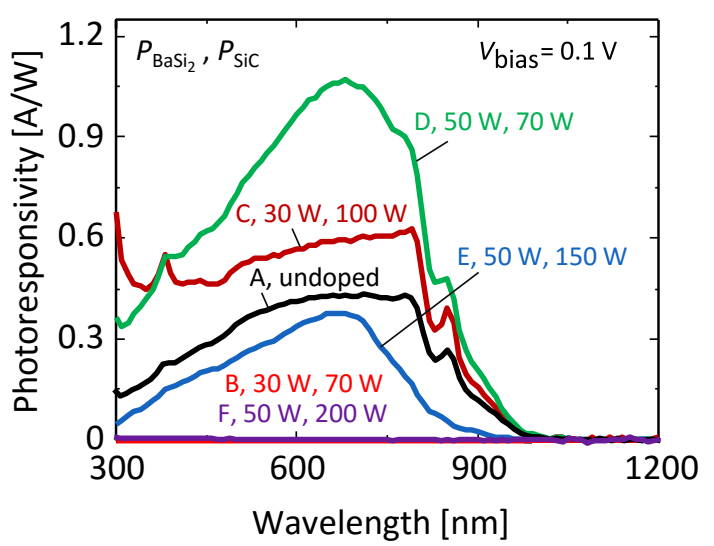

Fig. 5 


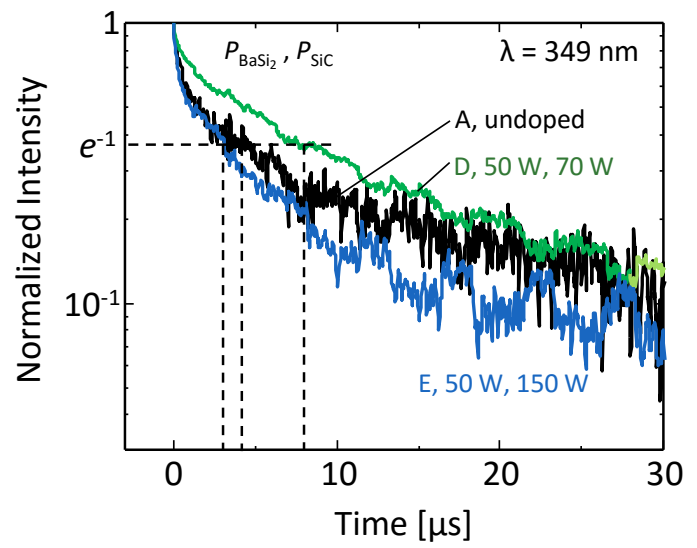

Fig. 6 